\title{
GESTÃO URBANA: PERSPECTIVAS QUANTO À PARTICIPAÇÃO DO GESTOR URBANO NAS DECISÕES ADMINISTRATIVAS MUNICIPAIS
}

\section{URBAN MANAGEMENT: PERSPECTIVES ON PARTICIPATION IN DECISIONS OF ADMINISTRATIVE MANAGER URBAN MUNICIPAL}

\author{
Luiz Antonio Miotti ${ }^{1}$, Dora Orth ${ }^{2}$
}

Recebido em 02 de março de 2011; recebido para revisão em 23 de março de 2011; aceito em 16 de maio de 2011; disponível on-line em 18 de julho de 2011

\section{PALAVRAS CHAVES: \\ Gestão urbana; \\ Descentralização; \\ Responsabilidades \\ Municipais.}

\section{KEYWORDS:}

Urban administration;

Decentralization;

Municipal District

Responsibilities.
RESUMO: O tema abordado é gestão urbana no Brasil quanto aos seus aspectos políticos. Busca apontar as características que vêm acompanhando a gestão urbana na contemporaneidade, como o reconhecimento das cidades, de seu crescimento e sua influência na evolução humana, discorrendo sobre as prerrogativas legais, que tornam a gestão urbana, responsabilidade do município, da participação da sociedade civil nas decisões de investimento, do papel do Estado como financiador e do reconhecimento da participação do gestor urbano nas decisões administrativas municipais. Da análise dos dados verificou-se que a descentralização conferida delegou aos municípios as responsabilidades e atribuições para com os serviços públicos e que a participação do gestor urbano nas decisões administrativas municipais pode ser providencial para uma nova perspectiva de gestão.

\begin{abstract}
The approached theme is urban administration in Brazil as for their political aspects. Search to point the characteristics that are accompanying the urban administration in the contemporary, as the recognition of the cities, of it growth and it influence in the human evolution, talking about the legal prerogatives that turn the administration urban responsibility of the municipal district, of the participation of the civil society in the investment decisions, of the paper of the State as backer and of the recognition of the urban manager's participation in the municipal administrative decisions. Of the analysis of the data it was verified that the checked decentralization delegated to the municipal districts the responsibilities and attributions to the public services and that the urban manager's participation in the municipal administrative decisions can be providential for a new administration perspective.
\end{abstract}

\footnotetext{
* Contato com os autores:

1 e-mail : lamiotti@gmail.com (L. A. Miotti)

Engenheiro Civil, Professor da UTFPR, Mestre em Engenharia Civil

2e-mail : ecv1dmo@ecv.ufsc.br (D. Orth)

Arquiteta, Doutora em Planejamento Territorial, Professora LABGEO/UFSC
}

ISSN: 2179-0612

C 2011 REEC - Todos os direitos reservados.

\section{INTRODUÇÃO}

Em paralelo à evolução humana e ao crescimento cultural, social e demográfico da população caminham as responsabilidades em bem administrar a evolução em níveis aceitáveis para a dignidade humana.

Vem sendo construído um consenso que as políticas públicas devem ser implementadas alicerçadas em elementos da democracia direta e de seus agregados: direito de participar, liberdade na condução 
da auto-estima, transparência nas atividades, eficiência na gestão dos recursos e ações concernentes ao desempenho da atividade pública.

$\mathrm{O}$ artigo tem por enfoque a temática gestão urbana no Brasil e suas perspectivas, sendo delimitado aos aspectos da política de gestão urbana face aos direitos do cidadão em fruir dos benefícios e à participação da sociedade civil na efetiva condução dessa gestão. Tem como objetivo apontar as características que vêm acompanhando a gestão urbana na contemporaneidade, como o reconhecimento das cidades, de seu crescimento e de sua influência na evolução humana, das prerrogativas legais que tornam a gestão urbana responsabilidade do município, da participação da sociedade civil nas decisões de investimento, do papel do Estado como financiador e do reconhecimento da participação do gestor urbano nas decisões administrativas municipais.

Estes objetivos são propostos em razão de que os profissionais da engenharia civil, e da arquitetura desempenham o papel de projetar e executar obras em várias modalidades no setor público ou privado e, no entanto, não participam do planejamento para a realização das mesmas, nem detêm poder de decisão política quanto à gestão urbana em si, com relação aos recursos financeiros e quanto à disposição e disponibilização das obras para uso e benefício da comunidade local.

A escolha do tema leva em conta que o elemento constitucional promove a garantia dos direitos a todos e neles se inclui o direito individual de participar, como gestor dos recursos coletivos e da oportunidade em inserir um novo olhar sobre as ocorrências da urbanização através do planejamento.

Sob o âmbito profissional, já se confirma que a administração é compreendida como "a mais importante atividade humana [...], pois é ela que viabiliza as demais" (PRADO, 2003, p. 23), fato que endossa a justificativa para que se estude o reconhecimento da participação do gestor urbano nas decisões administrativas municipais.

O método de abordagem é pesquisa exploratória que "têm como principal finalidade desenvolver, esclarecer e modificar conceitos e idéias, tendo em vista, a formulação de problemas mais precisos ou hipóteses pesquisáveis para estudos posteriores" (GIL, 1999, p. 43). O método de análise é dedutivo, partindo do particular e colocando a generalização como um produto posterior do trabalho de coleta de dados. As fontes de pesquisa são bibliográficas compondo-se de livros de leitura corrente e de referência, periódicos, impressos diversos, páginas de web sites, relatórios de simpósios e seminários, anais

\footnotetext{
${ }^{1}$ Cfe. Histoire de l'Urbanisme, PUF/85
}

de congresso, entre outros (GIL, 1999, p. 770; SANTOS, 2000, p. 29).

\section{GESTÃO URBANA}

Para abordar o tema gestão urbana, deve-se compreender que é no meio urbano onde ocorre a concentração da população para o desenvolvimento de atividades industriais, comerciais e de prestação de serviços. A hierarquia urbana se estabelece neste espaço, a partir dos produtos e serviços que as cidades têm para oferecer (A POPULAÇÃO E O ESPAÇO URBANO, 2011). Observa-se que "As áreas urbano-industriais representam a mais profunda modificação humana da superfície da Terra. Os efeitos da urbanização são altamente intensivos e, em muitos casos, expandem-se para muito além dos próprios limites das cidades" (O ESPAÇO EM TRANSFORMAÇÃO, 2011).

\subsection{Conceitos}

Só é possível pensar a gestão urbana mediante a compreensão de sua terminologia colocada por Orth (2006, p.2) de que: “A gestão é um processo dinâmico de utilização de conceitos, princípios e instrumentos na elaboração e execução de políticas públicas capazes de satisfazer os indivíduos e atingir o bem comum".

Souza (2001, p.1), porém, já questionou: o que entender por gestão? Não concebeu a idéia de que o termo gestão pudesse ou devesse substituir o termo planejamento, enfatizando que gestão e planejamento são duas coisas diferentes e assim definiu: "A gestão é a administração dos recursos [...] e dos problemas aqui e agora [...]; o planejamento é a preparação para o futuro [...] com o fito de evitar ou minimizar problemas e melhor explorar potencialidades". Com isso, gestão e planejamento urbanos devem ser concebidos e implementados de modo integrado, com o propósito de proporcionar um autêntico desenvolvimento urbano com o olhar voltado para o futuro.

Em outro registro encontra-se que "O planejamento não é uma ciência, nem uma técnica ... É uma prática, que se utiliza de conceitos e teorias de ciências vizinhas, como urbanismo, sociologia, economia, administração", que evoluem de acordo com a experiência da sociedade humana (ORTH, 2006, p. 40).

A referência ao urbanismo recebe de Orth (2006, p. 5) as definições de que este: "Recobre toda a ação consciente visando conceber, organizar, planejar ou transformar a cidade ou o espaço urbano"; "Disciplina nova com status de uma ciência e uma teoria da cidade..."

Para Santos (2003, p.1), o desenvolvimento urbano nos grandes centros tem sofrido com os problemas gerados pelo descaso com que a prática do urbanismo tinha sido tratada até agora, a ponto de permitir questionamentos acerca do tipo de desenvolvimento urbano que vem sendo realizado no Brasil. 
Deve ser considerado que no Brasil, de acordo com dados do Instituto Brasileiro de Geografia e Estatística (IBGE) $80 \%$ de sua população está concentrada nas cidades, significando 8 em cada 10 brasileiros morando em zonas urbanas, um fenômeno comum em grande parte do planeta (RUIZ, 2011).

Se a cidade "É um organismo vivo, mutante, dinâmico onde contrastes profundos existem"; o planejamento estabelece uma cidade virtual; a legislação define sua condição de ilegalidade enquanto fica a cargo da gestão pública a incorporação das áreas reconhecidas como ilegais, cabendo-lhe estender os serviços urbanizados. Trata-se de ver a cidade como um todo, um lugar num determinado momento, constituindo-se como resultante de ações de diversos elementos em diferentes níveis" (BORGES, 2000, p.2).

Assim, a dinâmica acelerada do crescimento urbano, os diferentes enfoques sobre a sua gestão, as contradições existentes e a necessidade de uma visão holística fazem da cidade o centro das preocupações dos mais variados profissionais dentro da administração pública, quer como objeto de conhecimento, quer como meio de trabalho. Saber interpretar, cruzar, avaliar, analisar a correlação entre as diversas variáveis existentes em um determinado local é de extrema importância para o gerenciamento e avaliação do impacto das políticas públicas sobre a cidade (BORGES, 2000, p. 3).

Santos (2003, p.1) acredita que um novo modo de desenvolvimento já vem sendo posto em prática, com pessoas optando por trabalhar próximas ao seu local de trabalho ou vice-versa e procurando uma melhor qualidade de vida, uma mesma busca "que movimenta esse modo novo e ao mesmo tempo gera também indícios de um movimento para a criação de um outro modo de desenvolvimento paralelo a este novo".

Cabe à gestão urbana atender a demanda em serviços públicos em atividades inerentes a circulação e transportes, comunicações, abastecimento de água, luz/energia, coleta de esgoto e lixo, controle de vetores de doenças, controle do uso e ocupação do solo, saúde, cemitérios e funerais, educação, cultura, esportes, segurança e justiça, habitação, feiras e mercados. Para isso necessita estrutura administrativa, recursos humanos, espaços físicos, equipamentos e materiais, tarifação e custeio, legislação, adequados e suficientes dados e informações municipais através de características autônomas, além de parceria com o Estado e com a iniciativa privada (ORTH, 2006, p.5-6).

A implantação de uma gestão urbana adequada não se dissocia do enfrentamento de dificuldades, incluindo aquelas que envolvem alterações de caráter cultural, consistindo em um processo lento, avaliado permanentemente e flexível a mudanças. "Por outro lado, o equilíbrio entre receita e despesa e a consequente otimização dos recursos disponíveis determinarão o sucesso de qualquer gestão" (ROSA, 2006, p. 5).
Uma situação que se apresenta diferentemente daquilo que o Ministério das Cidades (2004, p. 8) desejava em sua publicação:

As cidades brasileiras esperam passar por mudanças profundas que Ihes garantirão um futuro de desenvolvimento equilibrado e universalizarão o direito à moradia digna em um ambiente saudável para todos os brasileiros. Para tanto, as cidades têm de contar com fontes estáveis e seguras de financiamento para o desenvolvimento urbano, indispensáveis para que as cidades possam manter-se e expandir-se adequada e democraticamente.

No entanto, no Tema 10, Plano Diretor e Estudo de Impacto de Vizinhança, a necessidade de avaliar impactos é exigência contemporânea, diante do "escasseamento" dos recursos naturais, esgotamento dos grandes conglomerados urbanos e a degradação das relações de vizinhança, na busca individual de padrões de qualidade de vida.

Aliás, a Constituição Federal de 1988 estabelece em seu Art. 182. "A política de desenvolvimento urbano, executada pelo poder público municipal, conforme diretrizes gerais fixadas em lei, tem por objetivo ordenar o pleno desenvolvimento das funções sociais da cidade e garantir o bem-estar de seus habitantes", em atendimento à obrigatoriedade do Plano Diretor, instrumento básico da política de desenvolvimento e de expansão urbana.

Acerca do estabelecimento deste direito, Orth (2006, p. 31) assevera que "A gestão da cidade é uma atividade extremamente custosa e para viabilizá-la, a administração pública precisa de mecanismos de captação de recursos [...] para o financiamento das atividades urbanísticas". Para essa atividade são adotados modelos complexos e variados de gestão pública pelas organizações administrativas municipais.

Especialmente no Brasil, Frey (2003, p.4) enfoca o debate em torno da reforma e modernização do Estado e da gestão pública determinado por duas principais vertentes de reflexão teórica e de experiências práticas em gestão urbana: em uma delas confirma a abordagem à social democracia de cunho neoliberal, já que voltada à necessidade da modernização e do enxugamento do Estado; em outra, evoca a abordagem democrático-participativa "que visa estimular a organização da sociedade civil e promover a reestruturação dos mecanismos de decisão, em favor de um maior envolvimento da população". Objetiva maior eficiência e melhores resultados.

Providencialmente, Fernandes e Bonfim (2005, p.14) se pronunciaram a este respeito, pressupondo que "a participação e o modo de relacionamento das administrações com a sociedade civil são tomados como indicadores das possibilidades de mudança social efetiva na sociedade brasileira contemporânea", retrato daquilo que se entende como democracia deliberativa, fundada na democracia 
associativa. Tal participação tem como fim repensar o paradigma de funcionamento do Estado moldado pelas diretivas constitucionais, elemento fundador na proposição de políticas públicas.

Segundo o Instituto Brasileiro de Geografia e Estatística (IBGE, 2010), para o ano de 2009, 99,9\% dos municípios brasileiros confirmaram possuir estrutura organizacional para tratar da política de assistência social. A oferta de serviços socioassistenciais alcançou $98,6 \%$, demonstrada pelos altos percentuais de municípios que disseram oferecer serviços de proteção social básica, cerca de $97,9 \%$ e de proteção social especial, de $87,6 \%$.

Quanto à legislação e gestão, segundo dados do IBGE (2010, p.1):

A existência de Plano Municipal de Assistência Social chegou a 93,1\%, em 2009, e de Conselhos Municipais de Assistência Social era de $99,3 \%$. Apenas $67,6 \%$ dos municípios declararam a existência de comitê gestor para o Programa Bolsa Família. 97,7\% dos municípios possuíam Fundo Municipal de Assistência Municipal. Em 2009, 4.861 $(87,3 \%)$ dos municípios declararam receber cofinanciamento federal e/ou estadual para a função de assistência social.

No grupo de proteção especial, os serviços municipais de alta complexidade mostram $24,5 \%$ para o Acolhimento de Crianças e Adolescentes; 20,6\% para a oferta de Acolhimento de Idosos; para o Acolhimento para a População de Rua, os índices somam apenas $5,2 \%$, e, menor ainda para os Serviços de Acolhimento de Mulheres, com 2,7\%.

\subsection{Mudanças no Espaço Local}

Segundo Ferreira e Moreira (2000, p.4) desde antes de 1988 os governos locais trabalham pela descentralização do poder por meio de sucessivas emendas constitucionais demandando aumento dos recursos financeiros para os Estados e municípios e, uma maior participação popular. Nesta participação mais de cem (122) emendas populares foram encaminhadas ao Congresso Nacional desde a década de 1970. A descentralização brasileira conseguida na Constituição Federal de 1988, portanto, deveu-se, integramente, à ação dos estados e dos municípios.

Concorda Borges (2000, p. 2), que a municipalização dos serviços públicos, transferiu a ação da descentralização para os governos municipais, responsabilidades e atribuições como os serviços públicos de saúde, saneamento básico, administração de transporte e trânsito, exigindo respostas rápidas de prefeituras despreparadas para atendê-las. Sob esse novo modelo, o autor pergunta: como fazer com que o gestor público possa contar com tecnologias para tratar, interpretar e utilizar as informações de modo a enxergar a cidade e suas relações com totalidade? São estas dificuldades plurais que evocam o a participação popular e do gestor urbano nas decisões administrativas municipais.
O Ministério das Cidades (2004, p. 8) convoca todos os cidadãos para enfrentar um grande desafio de instituir formas de planejamento e controle do território municipal utilizando os potenciais, respeitando os limites do seu meio físico, e as potencialidades abertas pela existência de redes de transporte e logística em seus territórios de forma que "os impactos de seu crescimento e desenvolvimento não se traduzam em desequilíbrios e deseconomias". Foi a primeira etapa de um programa que previu o acesso a recursos financeiros, à capacitação e à assistência técnica.

“[...] experiências como dos mutirões mostraram a eficácia da parceria local para a reconstituição do tecido social dilacerado por anos de desigualdade social, graças à promoção de atividades comunitárias que incluíram até a auto-gestão dos recursos públicos". O orçamento participativo também conta como experiência bem fundada na gestão urbana sob a responsabilidade da sociedade civil (FERREIRA e MOREIRA, 2000, p. 7).

A prática do orçamento participativo tem despertado a atenção do cidadão bem como "o espanto de sua própria descoberta, de que aquele dinheiro é seu, de que se trata de coisa pública, de que nem tudo é cinismo e trambique", lembrando também que a sociedade é um organismo interativo e não reconstruída aos pedaços (DOWBOR, 2002, p. 37).

Com respeito ao orçamento participativo, Fórum Nacional de Participação Popular mostra que, entre 2001 e 2004, 140 municípios brasileiros haviam iniciado experiências de Orçamento Participativo (RUIZ, 2010).

A Figura 1 mostra o esboço de uma estruturação que poderia ser seguida para que, da gênese nas políticas públicas, a sociedade civil ascendesse ao plano de gestor urbano.

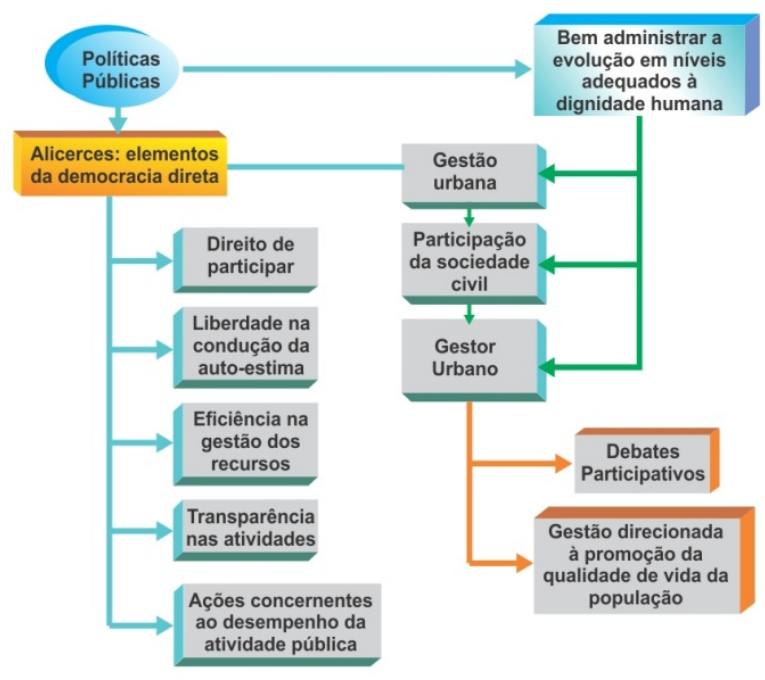

Figura 1: Roteiro para a participação da sociedade civil na gestão urbana. 
Assim, ao observar o Estatuto das Cidades (2001), consoante ao disposto sobre a urbanidade e a participação democrática, tem-se que:

Art. 20 A política urbana tem por objetivo ordenar o pleno desenvolvimento das funções sociais da cidade e da propriedade urbana, mediante as seguintes diretrizes gerais: I - garantia do direito a cidades sustentáveis, entendido como o direito à terra urbana, à moradia, ao saneamento ambiental, à infraestrutura urbana, ao transporte e aos serviços públicos, ao trabalho e ao lazer, para as presentes e futuras gerações; II - gestão democrática por meio da participação da população e de associações representativas dos vários segmentos da comunidade na formulação, execução e acompanhamento de planos, programas e projetos de desenvolvimento urbano; III - cooperação entre os governos, a iniciativa privada e os demais setores da sociedade no processo de urbanização, em atendimento ao interesse social.

Ferreira e Moreira (2000, p.1-3) já haviam denunciado que as grandes cidades estão crescendo nas periferias, reforçando a função estrutural da informalidade na composição do espaço urbano concomitante ao fato de que o Estado não se mostra senão alheio e ausente a qualquer obrigação de ordenação ou regulação da ocupação desse espaço urbano nas periferias. $\mathrm{Na}$ verdade, "a ação do Estado, na gestão da cidade não consegue responder às demandas por uma melhor qualidade do espaço urbano, e uma maior sustentabilidade das suas formas de produção".

Deste modo, a gestão local é reflexo das transformações engendradas no seio das relações socioeconômicas, políticas e culturais, não mais exclusivamente organizada de maneira hierárquica pelos atores públicos federal, estadual e municipal, mas, em razão do papel do Estado, essa gestão é definida cada vez mais pelos atores locais públicos e privados, ou seja, provocando uma abertura para o ingresso do gestor urbano (FERREIRA e MOREIRA, 2000, p.5).

Mais proximamente verificaram-se medidas legais para a adequada urbanização, com dotação de infraestrutura que garanta a qualidade de vida para os cidadãos. Como exemplo, em fevereiro de 2011, a Caixa Econômica Federal, financiadora do Programa Minha Casa Minha Vida estabelece medida restritiva à liberação de crédito para a habitação em locais nos quais não exista infraestrutura completa. Trata-se, sobretudo, de:

Um conjunto de normas que procuram dar uma garantia de qualidade de vida para o morador - o mínimo que deveria ser exigido de um projeto com apoio do governo, como por exemplo, ruas asfaltadas com meio-fio - e saneamento básico. [...] Existe um esforço mundial para levar saneamento básico para $100 \%$ dos habitantes do planeta. Oras, a primeira medida é não construir antes de preparar a infraestrutura básica (RUIZ, 2011, p.1).
O recado de Ruiz (2011) é para que seja considerado o aquecimento do mercado imobiliário, especialmente quanto ao seu enfoque na denominada Classe $C$, inclusive por meio do Programa Minha Casa Minha Vida, para pretender do Estado o cumprimento desta exigência. Aliás, para que se cumpra o disposto no Estatuto da Cidade e que os pequenos construtores levem aos prefeitos e vereadores a reivindicação para a elaboração de um Plano Diretor que atenda de modo amplo a população local, em especial quanto à democratização dos recursos públicos.

Entretanto, em março de 2001, em divulgação de nota, a Caixa Econômica Federal volta atrás em sua determinação restritiva de crédito para o financiamento habitacional e estende até o dia 30 de junho deste ano, o financiamento para imóveis em ruas sem asfalto, pelo Programa Minha Casa Minha Vida. A justificativa prevê a isenção de prejuízo para famílias que já haviam adquirido casas em locais sem asfalto e com pedido de financiamento deferido até fevereiro de 2011 (FORUM IMOBILIÁRIO, 2011).

\section{PERSPECTIVAS}

Os dados colhidos mostram que a descentralização das responsabilidades para os governos municipais sobre gestão urbana carece de programas que viabilizem os recursos e que a gestão e o planejamento sejam concebidos e implementados de modo integrado, viabilizando economicamente as estratégias formuladas e construindo cenários que favoreçam a visão a curto, médio e longo prazo.

É neste espaço que o gestor urbano poderia ter seu desempenho reconhecido e participar das decisões administrativas municipais, guiando-se pela prospecção e planejamento, dissociado das questões políticas partidárias e dos interesses particulares de grupos econômicos em situações do município. Sob a perspectiva de participação nas decisões administrativas municipais, o gestor urbano poderá mostrar aos empresários e aos futuros investidores que a cidade pode crescer e desenvolver-se de forma diferente, observadas as determinações quanto ao seu desenvolvimento e a legislação.

O Estado é pego desprevenido frente ao crescimento populacional e à efetiva destinação de recursos para bem administrar. Ainda que a Constituição Federal garanta os direitos, ao Estado e à sociedade cabem esforços para implementá-los.

Compreende-se que a participação do gestor urbano nas decisões administrativas municipais permitirá a promoção de parcerias, idealização de negócios que beneficiem a população, implementação do fundo rotativo municipal, que incentivem novas culturas agrícolas e aumento da renda familiar.

Baseado em uma visão ampla de administração pública sem ideologias políticas, caberá ao gestor urbano viabilizar a realização de debates 
participativos sobre a cidade com a população, com os empresários e a sociedade, realizar previsão acerca da evolução ou ascensão que o município poderá ter através da construção de cenários.

Além disso, decorrem de sua atuação a busca e utilização de novas tecnologias, de equipamentos e materiais adequados em parceria com pessoas que possuam conhecimento geral e específico, objetivando uma gestão direcionada à promoção da qualidade de vida da população.

\section{CONSIDERAÇÕES FINAIS}

Foi possível constatar que a descentralização conferida pela Constituição Federal de 1988 trouxe para os municípios as responsabilidades e atribuições como os serviços públicos de saúde, saneamento básico, educação e habitação, entre outros, encontrando um governo despreparado para uma gestão eficiente dos recursos disponíveis e para a elaboração de planejamento a curto, médio e longo prazo.

Verificou-se que a política urbana deve primar pela participação popular, formação de parcerias entre universidades, prefeitura e sociedade civil, analisar as perspectivas referenciais de inovações pré-definidas pelos governantes, disseminar as informações à população de forma clara, transparente e acessível.

Neste complexo compreendeu-se que o gestor urbano pode desempenhar um papel muito importante como participante das decisões administrativas municipais, com um olhar diferenciado sobre questões com o meio ambiente, de planejamento e de gestão, pela observação de valores dinâmicos, realizando análise das idéias formuladas por outros grupos em outras cidades e que servem como diretriz para reformulações e inserção de pessoas e de técnicas dotadas de bom senso e experiência.

Considerando o alcance de participação que a sociedade civil tem demonstrado no contexto social atual, as iniciativas individuais e coletivas vêm representando significativas diferenças no retorno social para a população, que exige o atendimento de suas necessidades. Os dados divulgados pelo IBGE (2010) confirmam que a população se organiza gradativamente para buscar os benefícios sociais, ou seja, os recursos do Estado passam a ser geridos localmente nos municípios.

Por fim, ressalta-se a importância em estudar o tema gestão urbana, pelo alcance social, econômico e de desenvolvimento que propicia à sociedade em geral.

\section{REFERÊNCIAS BIBLIOGRÁFICAS}

A POPULAÇÃO E O ESPAÇO URBANO. Disponível em: $<$ http://espacourbanotocolando.blogspot.com/ 2010/04/populacao-e-o-espaco-urbano.html> Acesso em: 28 fev.de 2011.
BORGES, K. A. V. A gestão urbana e as tecnologias de informação e comunicação. Revista IP - Informática Pública. Belo Horizonte, Ano2, n.2, p.17-24, dez. 2000.

BRASIL. Constituição Federal da República. Brasília, DF: Congresso Nacional, 1988

BRASIL. Lei no 10.257, de 10 de julho de 2001. Estatuto das Cidades. Brasília, DF: Congresso Nacional, 2001. Atos do Poder Legislativo Regulamenta os arts. 182 e 183 da Constituição Federal, estabelece diretrizes gerais da política urbana e dá outras providências.

DOWBOR, L. A comunidade inteligente: visitando as experiências de gestão local. In: CACCIA-BAVA, S.; PAULICS, V.; SPINK, P. Novos contornos da gestão local: conceitos em construção. São Paulo: Polis: Programa gestão Pública e Cidadania/FGV-EAESP, 2002.

FERNANDES, A. S. A.; BONFIM, W. L. de. Gestão Municipal e Participação Municipal no Brasil: Dialogando entre Teoria e Fatos. In: GT 01 - Cidades: Sociabilidades, cultura, participação e gestão XXIX Encontro Anual da ANPOCS- 25 a 29 de outubro de 2005.

FERREIRA, J. S. W.; MOREIRA, T. A. Governança urbana no contexto das cidades subdesenvolvidas. Anais... IX Congresso Ibero-Americano de Urbanismo. Recife, 27 a 30 novembro de 2000.

FREY, K. Gestão Urbana: um desafio interdisciplinar. In: I. Seminário Internacional em Gestão Urbana. Curitiba: PUCPR/PPGTU, 2003. v. 1.

FÓRUM IMOBILIÁRIO. Caixa Econômica volta a financiar casas em ruas sem asfalto pelo 'Minha Casa, Minha Vida'. Disponível em:

$<$ http://www.forumimobiliario.com.br/cidades/caixaeconomica-volta-a-financiar-casas-em-ruas-sem-asfalto-pelominha-casa-minha-vida/>. Acesso em: 11 maio 2011.

GIL, A. C. Métodos e técnicas de pesquisa social. São Paulo: Atlas, 1999.

INSTITUTO BRASILEIRO DE GEOGRAFIA E ESTATÍSTICA. IBGE 2010: $98,6 \%$ dos municípios declararam possuir serviços socioassistenciais, mas poucos supervisionam. Brasília, DF: IBGE, Comunicação Social, 21 maio 2010. Disponível em: <http://www.ibge.gov.br/home/presidencia/noticias/noticia_v isualiza.php?id_noticia $=1620 \& / d$ _pagina $=1>$. Acesso em: 10 maio 2011.

MINISTÉRIO DAS CIDADES. Plano Diretor Participativo. Brasília, DF: Congresso Nacional, 2004.

O ESPAÇO EM TRANSFORMAÇÃO. Disponível em: <http://www.oocities.org/geo_mundi/geral1.htm> Acesso em: 28 fev. 2011.

ORTH, D. Apostila Didática. Disciplina de Pós-Graduação Gestão Urbana. Florianópolis, março de 2006.

PRADO, J. R. Iniciação à administração: preceitos básicos. 6 . ed. São Paulo: Global, 2003.

ROSA, M. P. da. Resumo crítico do artigo "The transformation of Polish local government". Mestrado em Cadastro Técnico Multifinalitário e Gestão Territorial. Universidade Federal de Santa Catarina - USFC, 2006. 
RUIZ, José. Orçamento participativo: o que é isso? In: Fórum Imobiliário, 18 ago. 2010. Disponível em: < http://www.forumimobiliario.com.br/cidades/orcamentoparticipativo-o-que-e-isso/>. Acesso em: 11 maio 2011.

Ambientalismo, Estatuto da Cidade e Gestão Participativa. In: Fórum Imobiliário, 11 fev. 2011. Acesso em: 11 maio 2011.

. Minha Casa Minha Vida só no asfalto: bom ou mau? In: Fórum Imobiliário, 23 fev. 2011. Disponível em: <http://www.forumimobiliario.com.br/habitacao/minha-casaminha-vida-so-no-asfalto-bom-ou-mau/>. Acesso em: 11 maio 2011.

SANTOS, A. R. dos. Metodologia científica: a construção do conhecimento. 3. ed. Rio de Janeiro: DP\&A, 2000.

SANTOS, R. N. S. C. dos. Novas tecnologias versus desenvolvimento urbano. Texto Especial 194. Disponível em: <http://www.vitruvius.com.br/arquitextos/arq000/especial.as p>, agosto 2003. Acesso em: 8 de maio de 2006.

SOUZA, M. L. de. Problemas da Gestão Urbana no Brasil Contemporâneo: uma Panorâmica. Curso de gestão urbana e de cidades. EG/FJP WBI LILP ESAF IPEA. Disponível em: <http://www.eg.fjp.gov.br/gestaourbana/

arquivos/modulo01/mod1arq8.html> Acesso em: 8 de maio de 2006. 